\title{
143. L'influence de la bile sur la digestion de la substance protéique par le suc pancreatique.
}

\author{
par Saburo Matsukura. \\ (Clinique chirurgical de M. le Pr. Dr. H. Snuota, \\ l'Université impériale de Tokjo, Japon.)
}

(Rec. August 2nd 1926. Comm. by K. MiurA, M.I.A., Oct. 12, 1926.)

On conçoit facilement que l'activité digestive la plus puissante se trouve dans le duodénum à causo de la présence non sculement de la sécrétion ducdénale, mais encore de la bile et du suc pancréatique. On connaît déjà beaucoup sur l'action isolée de ces sécrétions, mais il y a grande ignorance encore aujourd'hui sur leur action simultanée. Or c'est précisément une les questions la: plus importantes dans l'étude du méchanisme de la digestion.

Pour éclairer sur ce point, suivant la méthode de Mett, j'ai mesuré les variations de la digestion de la substance protéique, en versant de la bile en quantité variée dans les mélange; déterminés du suc pancréatique et de l'extrait duodénal. Le suc pancréatique a été obtenue par la fistule temporaire du chien; la bile a été obtenue par la fistule du canal cholédoque après l'injection de pilocarpine hydrochlorique. Enfin le liquide supernatant de l'émulsion de la muqueuse duodénale dans dix volumes de l'eau physiologique a été utilisé comme extrait duodénal.

\begin{tabular}{|c|c|c|c|c|c|c|c|c|c|}
\hline tube & suc panc- & extrait & bile & eau , hys- & \multicolumn{5}{|c|}{ résultats parl' heures } \\
\hline $\mathrm{N}^{\circ}$ & c c. & c c. & c c. & c c. & $3^{\mathrm{h}}$ & $5^{h}$ & $12^{\mathrm{h}}$ & $15^{\mathrm{h}}$ & $20^{\mathrm{h}}$ \\
\hline 1 & 0.2 & 2.0 & 0.1 & 2.7 & 0 & léger & 1.0 & 2.0 & 3.0 \\
\hline 2 & 0.2 & 2.0 & 0.5 & 2.3 & 0 & léger & 1.0 & 2.0 & 3.0 \\
\hline 3 & 0.2 & 2.0 & 1.0 & 1.8 & 0 & léger & 1.0 & 3.0 & 3.5 \\
\hline 4 & 0.2 & 2.0 & 1.5 & 1.3 & 0 & léger & léger & 3.0 & 3.0 \\
\hline 5 & 0.2 & 2.0 & 2.0 & 0.8 & 0 & léger & léger & 2.0 & 3.0 \\
\hline 6 & 0.2 & 2.0 & 0 & 2.8 & 0 & 1.0 & 2.0 & 2.0 & 2.0 \\
\hline 7 & 0 & 2.0 & 0.5 & 2.5 & 0 & 0 & 0 & 0 & 0 \\
\hline 8 & 0.2 & 0 & 0.5 & 4.3 & 0 & 0 & 0 & 0 & 0 \\
\hline
\end{tabular}


Dans ce travail nous pouvons constater les faits suivants:

$1^{\circ} \quad$ La digestion du protéin par le suc pancréatique en présence du suc duodénal commence a apparaître le premier dans la série qui ne contient pas de la bile.

$2^{\circ}$ La bile a le pouvoir inhibiteur sur la digestion de protéin par le suc pancréatique dans les premiers heures.

$3^{\circ} \quad$ La bile, d'autre part, semble nécessaire pour que le suc pancréatique exerce plus longtemps son action digestive sur la substance protéique. 